\title{
The Influence of the Hydrogen Supply Modes on a Hydrogen Refueling Station
}

\author{
Min-Hon Rei*, Yu-Ling Kao, Guan-Ting Yeh, Shi-Chung Chen \\ Green Hydrotec Inc., Taiwan \\ Email: *reimh@grnhydrootec.com
}

How to cite this paper: Rei, M.-H., Kao, Y.-L., Yeh, G.-T., \& Chen, S.-C. (2020). The Influence of the Hydrogen Supply Modes on a Hydrogen Refueling Station. Modern Economy, 11, 867-880.

https://doi.org/10.4236/me.2020.114065

Received: February 22, 2020

Accepted: April 18, 2020

Published: April 21, 2020

Copyright $\odot 2020$ by author(s) and Scientific Research Publishing Inc. This work is licensed under the Creative Commons Attribution International License (CC BY 4.0).

http://creativecommons.org/licenses/by/4.0/ (c) (i) Open Access

\begin{abstract}
Setting up and operating a hydrogen refueling station is a critical part of current drive for fuel cell vehicles. In setting up a hydrogen refueling station (HRS), the investor concerns of the capacity of HRS, the quality of hydrogen, the capital requirement of the station and the modes of hydrogen supply; interestingly, the supply modes of hydrogen further influences the safety of the station, the cost of hydrogen, the energy consumption of supply and the area of hydrogen supply section in a station. Hydrogen can be supplied to a HRS by the procurement of the merchant hydrogen from a central source with the central hydrogen supply mode (CHSM) or by an onsite production of hydrogen in the distributed hydrogen supply mode (DHSM). In this presentation, the above factors are evaluated with respect to these two supply modes of hydrogen. It is concluded that the lower hydrogen cost and the smaller site area as well as the safer aspect of the public concern of safety can be realized with the choice of the distributed hydrogen supply mode by an onsite hydrogen production from methanol.
\end{abstract}

\section{Keywords}

Hydrogen Refueling Station, Central Hydrogen Supply Mode, Distributed Hydrogen Supply Mode, Onsite Hydrogen Production, Onsite Hydrogen Generator of Methanol, Costs of Hydrogen Supply, Safety and Area of Hydrogen Refueling Station

\section{Introduction}

Fuel cell marked a rapid growth after 2016 in the numbers of installations and in the power output of transaction, and the power output reached a milestone of 1.1 gigawatt at the end of 2019 (E4 Tech, 2019). Besides the installation of uninterrupted power supply (UPS) for the cellphone transmitter and of combined 
heat and power (CHP) in the residential home with a fuel cell power system, the rapid development of fuel cell electric vehicle (FCEV) has intensified the development pace of fuel cell activity and is expected to accelerate between 2020 and 2030 according to the report of Heid and coworkers (Heid et al., 2017). The successful introduction of Mirai FC-sedan by Toyota Motor Co. is a result of simultaneous setting up of well-located hydrogen refueling stations (HRS) service, the implementation of financial encouragement from company and governments, and above all, the reliable fuel cell power driving facility itself. The availability and the well located HRS are critical to the customer acceptance of FCEV in the early stage of promotion for users; more stations and lower cost of hydrogen will become important considerations to the driver and stimulate faster development of FCEV in the later stage of development.

In 2018 alone, 77 new HRS have been installed and a total of 303 active stations and a total of 367 stations with over 12,900 hydrogen vehicles in the world at the end of 2018, and both Japan and Germany, respectively, have had 109 and 70 stations as of Sep 30 of 2019 (Hydrogen Tools, 2019). The California development program for FCEV and HRS has steady growth in the registered on the road FCEV from 5014 in 2018 to 6826 in 2019 (as of Oct. 1st, 2019), and the number of operating HRS from 39 in 2018 to 39 - 41 station in actual operation with 21 station in the preparation in 2019 (Newsom, 2019). The worldwide construction of HRS is expected to speed up rapidly after 2018; it is forecasted that there will have 460 stations in 2020 and 1560 stations in 2025 (IEA, 2019). California has projected an aggressive development program to have $5923 \mathrm{FCEV}$

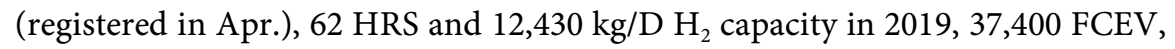
$102 \mathrm{HRS}$ and 30,680 kg/D H$~_{2}$ in 2023 and 48,000 FCEV, 214 HRS and 89,800 $\mathrm{kg} / \mathrm{D} \mathrm{H}_{2}$ in 2025 (CAR Board, 2019). Apparently, the investment or activity in the vehicle related fuel cell and hydrogen refueling stations appears to become the main thrust in the hydrogen economy.

\section{The Contents and the Capacity of a HRS}

In general, a HRS is composed of (1) a hydrogen supply facility, (2) a compressor system, (3) a cooling device and a heat exchanger to cool down the hydrogen temperature due to compression, (4) a tank cluster for the transit storage of the high-pressured hydrogen (45-85 MPa) and (5) a hydrogen dispensing device to deliver ultrahigh-pressured hydrogen into an onboard container of the vehicle ( 35 or $70 \mathrm{MPa}$ ) as shown in Figure 1.

Inside a Toyota Mirai sedan, there are two onboard $70 \mathrm{MPa}$ containers of $60 \mathrm{~L}$ and $62.4 \mathrm{~L}$ containing $5 \mathrm{~kg}$ of hydrogen under $70 \mathrm{MPa}$ pressure for a continuous driving of $504 \mathrm{~km}$. Most of the current hydrogen capacity of HRS is $700 \mathrm{~kg} / \mathrm{D}$ ( $350 \mathrm{Nmh}$ of hydrogen) in Japan and $180-500 \mathrm{~kg} / \mathrm{D}$ in California of US. However, the actual filling to the vehicles in Japan was $15,000 \mathrm{~kg} /$ month between Jan. and Jun. of 2018 in the current 100 stations with about 2580 hydrogen vehicles; thus, the average daily filling is only $5 \mathrm{~kg} / \mathrm{D}$ in each station out of $700 \mathrm{~kg} / \mathrm{D}$ capacity (Tetsufumi, 2018). In California of US, there are 39 and 62 stations (40 in 


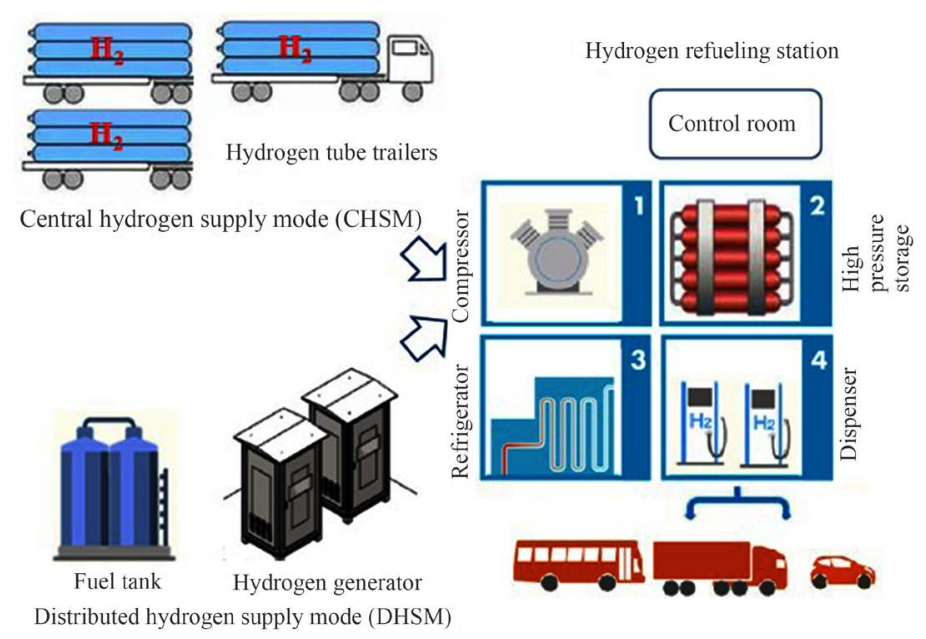

Figure 1. The contents of a hydrogen refueling station.

actual retail operation) with 4411 and 5923 FCEV in 2018 and 2019, respectively (Saur et al., 2019); however, the average actual hydrogen filling in each station is $80.9 \mathrm{~kg} / \mathrm{D}$ in the Q4 of 2019 with an average $34.4 \%$ of the installed capacity (Newsom, 2019). However, the daily dispensing profile of the station has about $78 \%-88 \%$ of daily capacity concentrated in $15 \mathrm{~h}$. between 7 am to $9 \mathrm{pm}$; this demands the additional inventory of hydrogen to maintain sufficient supply to keep up with the expanded filling in these busy hours, particularly on Friday (Newsom, 2019).

\section{The Quality of Hydrogen for HRS}

The hydrogen used for fuel cell in the hydrogen vehicle needs a high purity of 99.999\% with CO less than 0.2 ppm as suggested by ISO 14687 of 2012 (Ohi \& Nicholas, 2016). In Europe, the use of zero-carbon hydrogen is promoted and in Japan, the use of methanol for hydrogen production appears to be suppressed in favor of water electrolysis and natural gas steam reforming. That the rejection of methanol for hydrogen production in favor of the electrolysis of water and steam reforming of natural gas is a puzzle even though the production of hydrogen is simpler, lower investment and lower cost.

The production of hydrogen from methanol takes place in a single steam reforming step at $260-280^{\circ} \mathrm{C}$ to form $74 \%$ of hydrogen and $24 \%$ of carbon dioxide with CO concentration at $1.2 \%-1.6 \%$; it is then purified to $99.99-99.9995 \%$ for use in the fuel cell system. When natural gas is used for the hydrogen production, four catalytic processes are needed for the sulfur removal, steam reforming at 700 $900^{\circ} \mathrm{C}$ and high and low temperature shift reaction to lower CO from $15 \%-16 \%$ to $1.5 \%$. If electrolysis of water is used for hydrogen production, $4.0-4.5 \mathrm{kWh}$ of electricity is needed, tap water is deionized and the product hydrogen is further purified from 99.99 to $99.999 \%$ by selective oxidation and drying process. In these conversion processes, energy is consumed from the input process heat and the energy content of the reactant molecule itself. In the methanol process an energy of $142.7 \mathrm{MJ} / \mathrm{kg} \mathrm{H}_{2}, 160.5 \mathrm{MJ} / \mathrm{kg} \mathrm{H}_{2}$ and $194.4 \mathrm{MJ} / \mathrm{kg} \mathrm{H}_{2}$ are consumed in 
the processes of methanol, natural gas and electrolysis of water, respectively.

In general, there is a common desire to use renewable hydrogen to reduce carbon emission. There is a requirement of using a minimum 33\% of renewable hydrogen in the hydrogen supply to HRS with gradual increase to 35\% in 2025 and $40 \%$ eventually for all the public funded stations in 2030 in California (Newsom, 2019). With the actual difficulty to generate power from using $100 \%$ renewable source in a short period of time, a gradual increase of renewable hydrogen from $33 \%$ to higher percentage with time is a realistic approach under the current conditions.

Electrolysis of water is often favored for its $\mathrm{CO}_{2}$-free in hydrogen production at the site if the electricity is generated from renewable source, not from the burning of fossil fuel. However, at present time most of the electricity source is laden with heavy $\mathrm{CO}_{2}$-emission, e.g. $0.4-0.6 \mathrm{~kg} / \mathrm{kWh}$ due to the use of fossil fuel as the common source. With a general efficiency of $4.0-4.5 \mathrm{kWh} / \mathrm{m}^{3} \mathrm{H}_{2}$ (or 48 $54 \mathrm{kWh} / \mathrm{kg} \mathrm{H}_{2}$ ) in the electrolysis of water to hydrogen, this means that there is about $24-27 \mathrm{~kg} \mathrm{CO}_{2}$ for each kilogram of hydrogen delivered to a HRS. In the steam reforming of methanol and of natural gas to hydrogen, $8.95 \mathrm{~kg} \mathrm{CO} / 2 \mathrm{kgH}_{2}$ and $8.47 \mathrm{~kg} \mathrm{CO}_{2} / \mathrm{kgH}_{2}$, respectively, is generated from their reforming reactions. However, if the compression of natural gas during distribution is taken into consideration, the overall $\mathrm{CO}_{2}$ emission in the steam reforming of natural gas becomes $9.38 \mathrm{~kg} \mathrm{CO}_{2} / \mathrm{kg} \mathrm{H}_{2}$ while that from methanol remains unchanged at 8.95 $\mathrm{kg} \mathrm{CO}_{2} / \mathrm{kg} \mathrm{H}_{2}$ (Rei, 2020). As such, methanol should be treated equally with or favorably over that from natural gas for the hydrogen production based on the consideration of energy consumption, $\mathrm{CO}_{2}$ emission and the simplicity of the process.

Conceivably, if an onsite hydrogen generator from methanol is used, the energy consumption is only $2 / 3$ and the $\mathrm{CO}_{2}$ emission is only $1 / 3$ of that from the electrolysis of water with the conventional electric power. This level of $\mathrm{CO}_{2}$ emission may be close to a net $67 \%-60 \%$ level of $\mathrm{CO}_{2}$ in the California regulation toward 2040. This will be a realistic way to approach the gradual reduction of $\mathrm{CO}_{2}$ emission until a low-pressure process of reducing $\mathrm{CO}_{2}$ with hydrogen to form methanol back become practical (e.g. using a more reactive catalyst like nano-sized catalyst) to allow onsite capture of $\mathrm{CO}_{2}$. Once such a low pressure reduction of $\mathrm{CO}_{2}$ by hydrogen becomes available and it is used for onsite capture of $\mathrm{CO}_{2}$ to avoid large scale collection and high shipping cost of $\mathrm{CO}_{2}$ to a central methanol plant, it would imply that the use of onsite hydrogen production from methanol would not only reduce the cost of hydrogen but also reduce carbon emission.

\section{The Supply Modes of Hydrogen to the Fueling Station}

To a HRS, the hydrogen can be supplied with two modes, the central hydrogen supply mode (CHSM) or the distributed hydrogen supply mode (DHSM). The hydrogen supply to the HRS in US or in Europe is mainly the merchant hydrogen delivered by outside contractor such as industrial gas companies with compressed hydrogen in the long tube trailer or with liquefied hydrogen in the cryogenic container. The hydrogen is delivered from a large central hydrogen source to the user or a hydrogen station in the central hydrogen supply mode (CHSM); 
in this mode, hydrogen in the central source is obtained either from the recovery of hydrogen by-product of various allied industries such as alkali/chlorine plant, petrochemical complex, steel manufacturing plant or from a hydrogen production plant using one of the three industrial processes: the electrolysis of water, the steam reforming of methane (natural gas or shale gas) or the steaming reforming of methanol. The crude hydrogen recovered from by-product or from plant production is purified to the required specification; the purified hydrogen is then compressed to high-pressure and placed in a pressure container or liquified as liquid hydrogen in a cryogenic container for the shipment to the users.

Often a $300 \mathrm{~kg}$ long tube trailer containing $3600 \mathrm{~m}^{3}$ of hydrogen at a pressure of $15-25 \mathrm{MPa}$ is used for shipping and storage in the station by one or more trailers to supply the required hydrogen; the trailer will then be parked inside the HRS. Besides the haul-in merchant hydrogen at 15 - $25 \mathrm{MPa}$, the hydrogen is further compressed up to 40 or $80 \mathrm{MPa}$ and stored in the transit high pressure tubes for dispensing to the onboard storage container of the hydrogen in the vehicles.

On the other hand, in a distributed hydrogen supply mode (DHSM), hydrogen is supplied by an onsite hydrogen generator in a HRS; in the station, only a proper amount of hydrogen in low pressure $(0.5-2.0 \mathrm{MPa})$ is produced by one of three industrial processes. Inside the station, the storage of large quantity of medium high pressurized hydrogen $(15-20 \mathrm{MPa})$ is not required (National Research Council, 2004). Unlike US, Europe and Japan, the hydrogen supply from the onsite steam reforming of methanol is interestingly getting greater attention in Taiwan and mainland China as it is more efficient and requires less energy supply and lower investment cost.

In the DHSM, hydrogen is produced from a fuel by a suitable process facility to the desirable specification in the site of a HRS for operation. To make enough hydrogen for the operation, the required reactant and fuel are shipped in by pipeline or by vehicle and stored onsite for the continuous preparation of hydrogen. If electrolysis of water is used, tap-water is processed to remove metal ion content and other impurity and the high voltage electricity is transformed to the low voltage for use; the hydrogen product from electrolyzer is further purified to remove oxygen, nitrogen and moisture.

If steam reforming of natural gas is used, it is generally piped in by a pipeline network; a compressor is often required to boost the pressure to $0.2-2.5 \mathrm{MPa}$ for the hydrogen production because natural gas in the urban area is often maintained in a low pressure of $0.02-0.03 \mathrm{MPa}$ for safety sake. The steam reforming of natural gas is conducted at a temperature of $700^{\circ} \mathrm{C}-900^{\circ} \mathrm{C}$ after sulfur impurity is removed by adsorption with active carbon or by catalytic removal at about $400^{\circ} \mathrm{C}$, the product mixture from the steam reforming is then treated with high temperature and low temperature water gas shift reactions to reduced CO from about $15 \%$ to $1.5 \%-2.5 \%$ before it is further purified with the selective catalytic adsorption with pressure swinging (PSA) or with hydrogen permeation by Pd-membrane to a higher hydrogen purity of $99.995 \%-99.9995 \%$. For area without natural gas pipeline, liquid fuel such as methanol or kerosene is often 
used for the preparation of hydrogen by the steam reforming process.

When methanol is used, it is steam reformed at $250^{\circ} \mathrm{C}-290^{\circ} \mathrm{C}$ into $\mathrm{H}_{2} / \mathrm{CO}_{2}$ mixture with $\mathrm{CO}$ at $1 \%-2 \%$ in one single step; the crude hydrogen is further purified with PSA or Pd-membrane to a $99.995 \%$ - 99.9995\% purity. Methanol is weakly toxic and is often classified as a hazardous chemical requiring special permission for storage; however, it is considered as a generally safer fuel than gasoline, diesel oil as stated by US Department of Energy (US Department of Energy, 1991). Methanol is a liquid with a boiling point of $64.7^{\circ} \mathrm{C}$ and can be distributed with the conventional shipping facility and service and is stored in the steel tank. It is miscible with water and can be readily extinguished by flushing with water in the case of fire from leakage (Figure 2).

The influence of the above two different hydrogen supply modes on a HRS is (1) the safety concern on the storage, (2) the cost of hydrogen supply, (3) the energy consumption in compacting of hydrogen during the distribution of hydrogen and (4) the area for supplying hydrogen inside the station.

\section{(1) The safety consideration of HRS}

As mentioned above that there will have huge quantity, $3600-7200 \mathrm{~m}^{3}$ or more of hydrogen with a pressure of $15 \mathrm{MPa}$ to $25 \mathrm{MPa}$ stored in a station by CHSM; on the other hand, there is none or much less storage of high-pressure hydrogen inside the station by DHSM. In the CHSM, when it is replaced with a new shipment of hydrogen trailer, reconnections of valves and venting of hydrogen content to flush certain piping section is needed. In the report of Zalosh and Short (Zalosh \& Short, 1978) for DOE US on the hydrogen accidents of US industries between 1966 and 1977, of the 409 total incidents reported, the incidents attributed to the piping, tubing valves, connectors and tube trailer or tank system from leakages, purging, ventilation, vessels and pipe rupture, venting accounted for 259 cases; this type of incidents will be worsen with the increase of volume and storage pressure. Interestingly, the electrolysis cell for the hydrogen production, battery and natural gas reformer had 8, 6 and 14 cases, respectively. The experience on HRS operation in California for the last 3-years also confirms accident associated with valve reconnection and pipe-flushing (Saur et al., 2019). The European Commission has initiated an international report system of Hydrogen Incidents and Accidents Data (HIAD) system to compile the hydrogen related incidents and accidents. This trend is compatible with the recent three accidents in a single month of June of 2019 in Korea, California and in Norway, by high-pressure hydrogen storage vessels or tanks (Herald, 2019; Pena, 2019; Fuelcellsworks, 2019). Incident from leakage or burst of high-pressure hydrogen can thus be minimized in a DHSM station in which the hydrogen pressure from the hydrogen generator is low with a limited volume and the piping and valve system is checked before installation without further adjustment needed after operation. Steam reforming of methanol is expected to be safer than these two processes because of its simpler process (only 1-catalytic process with methanol vs 4 -catalytic processes with natural gas) and lower reaction temperature $\left(250^{\circ} \mathrm{C}\right.$ $-280^{\circ} \mathrm{C}$ for methanol vs $700^{\circ} \mathrm{C}-900^{\circ} \mathrm{C}$ for natural gas). 


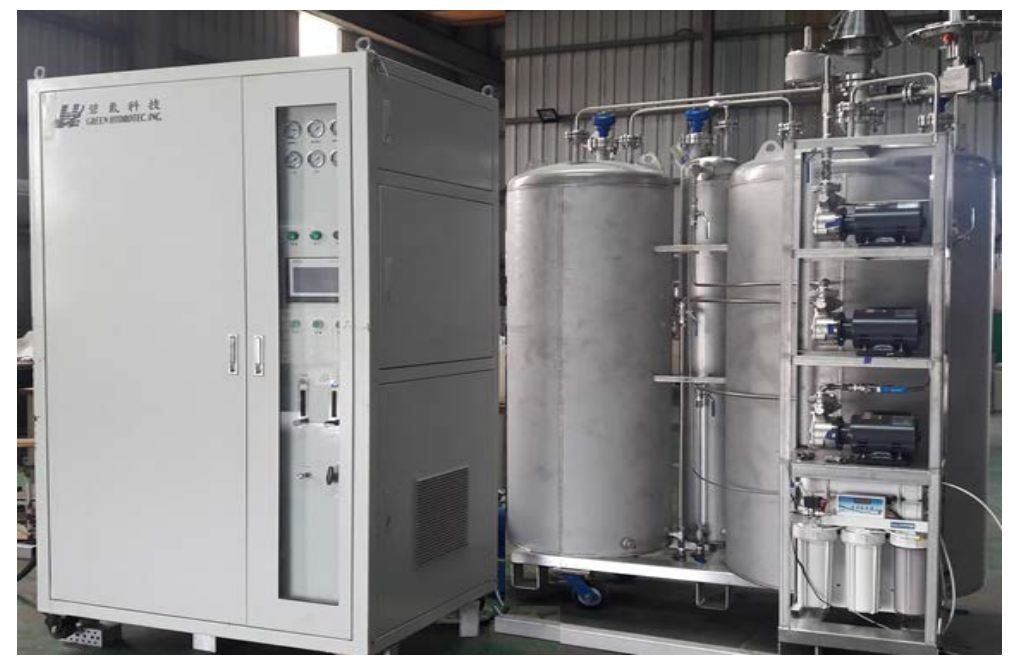

Figure 2. A $40 \mathrm{~kg} / \mathrm{D}$ onsite hydrogen generator from methanol by Green Hydrotec Inc.

In different countries, there will have additional safety codes regulating the need of partition some safety distance may be required for the trailer, production site or high-pressure section to keep from the nearby operation or structure.

(2) The cost of investment and the cost of hydrogen fuel

The cost of a HRS has been discussed in several publications in the past 10 years; Melaina and Penev in their NREL Technical Report classified the development of HRS into 4 categories based on the capacity of the developmental stages (Melaina \& Penev, 2013). The state of art station in 2011-2012 (I) had an average capacity of $160 \mathrm{~kg} / \mathrm{D}$ with an investment cost of $\$ 2.65$ million or an average unit cost of $\$ 16,570$ per $\mathrm{kg} / \mathrm{D}$. The early commercial station of $450 \mathrm{~kg} / \mathrm{D}$ between $2014-2016$ (II) requires $\$ 2.80$ million capital and an average unit cost of $\$ 6220 / \mathrm{kg} / \mathrm{D}$ whereas after 2016 with more stations of $600 \mathrm{~kg} / \mathrm{D}$ (III) and large station $1500 \mathrm{~kg} / \mathrm{D}$ (IV), their total investment will be $\$ 3.09$ million for (III) and $\$ 5.15$ million for (IV), respectively, with the corresponding unit cost reduced to $\$ 5150$ and $\$ 3370$ per $\mathrm{kg} / \mathrm{D}$. That Report also compared the unit cost $(\$ /(\mathrm{kg} / \mathrm{D})$ ) for a $400 \mathrm{~kg} / \mathrm{D}$ station with truck delivery of compressed hydrogen and of liquid hydrogen and by onsite production with natural gas and with electrolysis; in 2010, the unit costs were $\$ 5111$ and $\$ 4305$ for the compressed and liquid hydrogen delivery, respectively and $\$ 5182$ (\$3482 in 2020) and \$5242 (\$3811 in 2020) for the onsite production from natural gas and from electrolysis, respectively. Hecht and Pratt of Sandia National Laboratory for NREL in 2017 compared the capital cost and hydrogen cost by different supply modes (Joseph \& Pratt, 2017). There appears to be no drastic decrease in cost between the two estimates in 2010 and 2017. The 2017 report of unit capital investment (per $\mathrm{kg} / \mathrm{D}$ ) for a $300 \mathrm{~kg} / \mathrm{D}$ was $\$ 7000$ for the delivered hydrogen and $\$ 11,700$ or $\$ 11,200$ for the onsite production by natural gas or by electrolysis, respectively; the unit cost of hydrogen in the above sequence was $\$ 14.26, \$ 20.23$ or $\$ 21.74 / \mathrm{kg}$ of $\mathrm{H}_{2}$, respectively. These figures indicate an advantage of the central supply by merchant hydrogen over onsite pro- 
duction of hydrogen by either natural gas or electrolysis routes in US industry. This could be attributed to the exclusion of the cost of hydrogen delivery facility such as tube trailer or cryogenic tank lorry in the calculation of station investment or to the high capital cost for the small scale onsite production facility in US because of the scarce availability of small scale onsite production facility in the market.

The capital investment of a HRS in Japan is quoted to be $\$ 4.3$ million; however, the public supports from the national and metropolitan governments reduce the figure to about $\$ 870,000$ for the investor (Lewis, 2013). The hydrogen supply to the most of the HRS in Japan is merchant hydrogen from industrial gas companies; this enables the reduction of the initial investment cost by avoid paying the cost of onsite hydrogen production facility. China is actively promoting hydrogen energy program for vehicles and HRS and has near 1600 FCEV and 18 HRS in 2019 (Wandel, 2018). China has adapted $35 \mathrm{MPa}$ pressure system for her onboard hydrogen storage for heavy trucks and buses as the development targets; as a result, the HRS tends to be in $600-1000 \mathrm{~kg} / \mathrm{D}$ capacity. The cost of HRS for such sized capacity is quoted to be around $\$ 2-3$ million in the trade report, rather inexpensive for this capacity range of the station. The detailed breaking down of the cost structure is available from the two early publications in 2006 (Weinert et al., 2007) and 2016 (Liu et al., 2016); the latter, however, reported a high value of $\$ 7.84$ million for a $1000 \mathrm{~kg} / \mathrm{D}$ station. Besides the 2006 report, there is no recent detail report on the cost of the individual components in a HRS; it is not clear how the low cost of HRS in China is obtained because most of the pressure components of HRS are imported from abroad even for the CHSM which dominates current HRS installation. The government supports from the central and the local government amount to about \$600,000 (RMB 4 million) and is related to the capacity of station. This may have encouraged the investor to build larger station than the market actually needs; the number of hydrogen vehicles in China is less than 1800 today in the three urban regions of Beijing, Shanghai and Guangzhou having a combined area much larger than that of California which has 6826 FCEV and 39 - 41 HRS with capacity of 180 and $500 \mathrm{~kg} / \mathrm{D}$.

The cost of hydrogen supply delivered to station from merchant hydrogen source is $\$ 5.1-7.4 / \mathrm{kg}$ (RMB35 - 50/kg) in mainland China, \$10 - \$15/kg (JPD1000 $1200 / \mathrm{kg}$ ) in Japan (Nagashima, 2018) and the average retail price of $16.51 / \mathrm{kg}$ in California (Newsom, 2019). These hydrogen costs are much higher than $\$ 3.20 / \mathrm{kg} \mathrm{H}_{2}$ or $\$ 2.47 / \mathrm{kg} \mathrm{H}_{2}$ by an onsite hydrogen production from methanol plant of 300 $\mathrm{m}^{3} / \mathrm{h}(600 \mathrm{~kg} / \mathrm{D})$ if methanol is assumed to be $\$ 420 /$ ton or $\$ 240 /$ ton which is the international import price to Taiwan on March 27, 2020 (Green Hydrotec, 2019).

In a HRS, the cost of compressor, transfer tanks, dispenser and the office can be assumed to be about the same in both CHSM and DHSM; the facility cost of the hydrogen supply, tube trailers supply in CHSM and that of onsite production system by a methanol steam reformer in the DHSM, will be the major difference 
in a HRS of CHSM vs DHSM. The hydrogen supply system of a $200 \mathrm{~kg} / \mathrm{D}$ will need two or three tube trailers; one at the station and one or two more on the road or in preparation at the hydrogen plant plus an engine cab to haul the trailer. Whereas a $600 \mathrm{~kg} / \mathrm{D}$ station will need three or four trailers in addition to one or two engine cab. The cost of a $300 \mathrm{~kg}$ hydrogen long tube trailer and of its cab, respectively, are reported to be $\$ 210,000$ and $\$ 90,000$ each (Yang \& Ogden, 2007); the cost of the long tube trailer supply facility in a $200 \mathrm{~kg} / \mathrm{D}$ or $600 \mathrm{~kg} / \mathrm{D}$ HRS by CHSM will then be $\$ 210,000 \times 2$ (or 3 ) $+\$ 90,000=\$ 510,000$ or $\$ 930,000$, respectively. The corresponding hydrogen supply facility in a DHSM by the hydrogen generator from methanol is only $\$ 425,000$ and $\$ 830,000$ for 200 $\mathrm{kg} / \mathrm{D}$ or $600 \mathrm{~kg} / \mathrm{D}$ in Taiwan, respectively (Green Hydrotec, 2019). Thus, the cost for the hydrogen supply facility in the CHSM will be slightly higher than those in the DHSM at least in Taiwan.

\section{(3) Energy consumption for compacting during distribution}

Energy is consumed during hydrogen distribution for compression or for liquefaction to make volume more compact and shipping cost down. The adiabatic energy required in compressing hydrogen from ambient pressure $\left(\mathrm{P}_{\mathrm{o}}\right)$ to 20 $\mathrm{MPa}\left(\mathrm{P}_{1}\right)$ and $70 \mathrm{MPa}\left(\mathrm{P}_{2}\right)$ are $14.0 \mathrm{MJ} / \mathrm{kg}$ and $21.8 \mathrm{MJ} / \mathrm{kg}$, respectively, as calculated from $\mathrm{W}(\mathrm{J} / \mathrm{kg})=[\mu /(\mu-1)] \mathrm{p}_{0} \mathrm{~V}_{\mathrm{o}}\left[\left(\mathrm{p}_{1} / \mathrm{p}_{0}\right)^{(\mu-1) / \mu}-1\right]$ with $\mu=1.41 \mathrm{Vo}=11.11$ $\mathrm{m}^{3} / \mathrm{kg}$ for hydrogen and the corresponding energy equivalence is $10 \%$ and $15.6 \%$ and $40 \mathrm{MJ} / \mathrm{kg}$ (30\% of HHV of hydrogen) is needed for the liquefaction of hydrogen as shown in Figure 3 (Bossel \& Eliasson, 2003; Cardella et al., 2017). For compressing methane from ambient pressure to $20 \mathrm{MPa}$, it is $1400 \mathrm{~kJ} / \mathrm{kg}$ by calculation with $\mu=1.31$ and $\mathrm{Vo}_{0}=1.39 \mathrm{~m}^{3} / \mathrm{kg}$ (Bossel \& Eliasson, 2003). For the liquefaction of methane, power consumption of $2900 \mathrm{~kJ} / \mathrm{kg}(0.806 \mathrm{kWh} / \mathrm{kg} \mathrm{LNG})$ is needed as shown in Figure 3 (Franco \& Casarosa, 2014).

Thus, an energy in equivalent to $10 \%$ to $30 \%$ of hydrogen content is consumed in compacting hydrogen for distribution in addition to the investment in the equipment for the transportation (Amos, 1998). In the CHSM, 40\%-65\% of the sale price is often attributed to the expenses aroused between the original source and the user. In DHSM, hydrogen is produced in the station with its raw material shipped in from outside to the station. Natural gas can be forwarded to the station often by pipeline under a pressure of $5 \mathrm{MPa}$ or $20 \mathrm{MPa}$ or even lower than $0.1 \mathrm{MPa}$ for the urban area. If methanol is used for the onsite hydrogen production, it can be distributed with the ordinary tank for shipment. In Taiwan, mainland China or Japan, the environmental authority generally requires a permit for operation or storage and has a restriction of $400 \mathrm{~L}$ for storage in general working place unless it is diluted with water to less than $60 \%$ in a methanol/water mixture. As a result, Green Hydrotec Inc now recommends shipment of $55 \%$ to $59 \%$ of methanol/water mixture to the user as the feed for hydrogen and fuel for heating the reactor. This direct shipment of methanol/water simplifies the work for the site preparation of feed mixture at the expense of higher cost in the shipment of feed and fuel and of the energy consumption of heating up the system. 


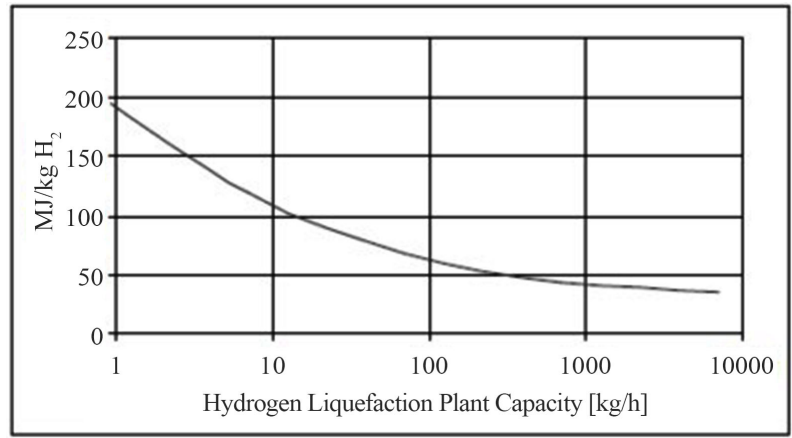

Figure 3. Typical energy requirements for the liquefaction of $1 \mathrm{~kg}$ hydrogen as a function of plant size and process optimization (Bossel \& Eliasson, 2003).

\section{(4) The site area of hydrogen supply section in a HRS}

Of the four sections of a HRS, the site area of the hydrogen sourcing section is the only section that will be influenced by the different hydrogen supply modes, CHSM or DHSM. In a CHSM, hydrogen is supplied and stored in one or more long tube trailers; the trailers will need a parking space for the service and replacement trailers with $1.85 \mathrm{~m}$ partition in addition to the driveway for the trailer to drive in. The parking space for a $300 \mathrm{~kg}$ tube trailer has a minimum dimension of $2.44 \mathrm{~mW} \times 14.2 \mathrm{~mL} \times 2.95 \mathrm{mH}$; the parking area in a $200 \mathrm{~kg} / \mathrm{D}$ or $600 \mathrm{~kg} / \mathrm{D}$ station having one or two trailers plus a replacement trailer with 1.85 $\mathrm{m}$ separation will be $95.6 \mathrm{~m}^{2}(14.2 \mathrm{~m} \times(2 \times 2.44 \mathrm{~m}+1.85 \mathrm{~m}))$ or $156.5 \mathrm{~m}^{2}(14.2$ $\mathrm{m} \times(3 \times 2.44 \mathrm{~m}+2 \times 1.85 \mathrm{~m}))$, respectively. In a DHSM station, this section will be occupied by the actual space for an onsite hydrogen production facility including the raw materials preparation with a proper buffer distance between the equipment; the methanol hydrogen generator for $100 \mathrm{Nmh}(200 \mathrm{~kg} / \mathrm{D})$ or 300 $\mathrm{Nmh}(600 \mathrm{~kg} / \mathrm{D})$ can be installed inside two $20 \mathrm{Ft}$ or $40 \mathrm{Ft}$ containers. The area for setting up two $20 \mathrm{ft}$ or $40 \mathrm{Ft}$-container will be $29.8 \mathrm{~m}^{2}(2 \times 2.44 \mathrm{~m} \times 6.1 \mathrm{~m})$ or $59.6 \mathrm{~m}^{2}(2 \times 2.44 \mathrm{~m} \times 12.2 \mathrm{~m})$, it is only $31 \%$ or $38 \%$ of the space required for hydrogen supply by the long tube trailers in a CHSM site. For a HRS in a busy urbane street side, this reduction in the site area will be a significant saving.

\section{Discussion}

The hydrogen dispensing profile in the HRS of California shows that there is a busy filling period of 11 hours between 7 am to $6 \mathrm{pm}$ or 8 am to $7 \mathrm{pm}$; the average filling percentage of hydrogen in this period is about $6 \%$ of the daily capacity with $7 \%$ in the 2-hours evening rush hours of 5 pm- $6 \mathrm{pm}$ or $6 \mathrm{pm}$ to $7 \mathrm{pm}$ depending on the locations of California, the southern or the northern regions (Newsom, 2019). For instance, a $200 \mathrm{~kg} / \mathrm{D}$ station will need an hourly supply of $14 \mathrm{~kg}$ hydrogen for 11 hours instead of $8.3 \mathrm{~kg}$ for 24 hours even demand. This $70 \%$ increase of dispensing volume can be met by the additional shipment of the hydrogen trailer in CHSM. In a DHSM, a larger production unit of $340 \mathrm{~kg} / \mathrm{D}$ with hourly production capacity of $170 \mathrm{Nmh}(340 \times 12 / 24)$ to meet the 11 hours busy time demand; alternatively the original $200 \mathrm{~kg} / \mathrm{D}(100 \mathrm{Nmh})$ unit can be 
supplemented with an additional transit storage facility for $63 \mathrm{~kg}\left(756 \mathrm{~m}^{3}\right)$ of hydrogen to store the hydrogen during the midnight off-hours production. This can be met with 2 long tubes (2200 L water volume) or 5-sets of $20 \times 40$ L-cylinder bundles at $20 \mathrm{MPa}$ pressure. The choice of these two options will depend on the economy of installing a larger hydrogen generator at the beginning or by that of installing a storage facility for the off-hour hydrogen production with a 24-hours continuous production. Our experience with the onsite hydrogen generator shows that it is more stable and reliable with the continuous operation of a hydrogen generator in the industrial plant than those intermittent on-off operation generators in the UPS type operation with the problem of unsteady $\mathrm{CO}$ concentration at the frequent start-up.

In CHSM, additional energy is required to compress or to liquefy hydrogen for increase of density besides the fuel for driving the vehicle. In the DHSM, methanol or natural gas is to be forwarded from a depot to the HRS; in the case of methanol, only the fuel for the vehicle driving is needed. Even in the case that natural gas is used in the onsite production of hydrogen for DHSM, the energy spent for compressing natural gas is much less than that of hydrogen (Bossel \& Eliasson, 2003).

The above elaboration has clearly indicated four advantages of the distributed hydrogen supply mode with onsite methanol hydrogen production in a DHSM over the haul-in merchant hydrogen in a CHSM for the HRS; the advantages of DHSM show up in (1) the lower cost of hydrogen, (2) the better safety aspect from the absence of storing or lesser storage of high-pressure hydrogen inside the station, (3) consumption of more energy during distribution in the CHSM and (4) the saving of the land use for the hydrogen supply facility.

While most stations tend to have large hydrogen capacity of $500-700 \mathrm{~kg} / \mathrm{D}$ in Japan and in California, the actual filling is mostly under $40 \%$ of the capacity as presented earlier. Perhaps a smaller station capacity, say $200-400 \mathrm{~kg} / \mathrm{D}$ or even smaller at $100-200 \mathrm{~kg} / \mathrm{D}$, with onsite production of hydrogen from methanol in a community style distribution or sharing with the existing gas stations, may provide a better service to the driver in term of economy, safety and convenience. This also avoids traffic congestion around a large HRS and avoids safety threat from storing large volume of high-pressure hydrogen in a CHSM station.

Future consideration of building a HRS may have to consider the strong public objection to the storage of large volume of high-pressure hydrogen in a HRS which locates mainly in the crowded area; this is a rising concern in view of the recent hydrogen explosion in a single month of June of 2019. As mentioned above with the US experience (Zalosh \& Short, 1978), the majority of hydrogen accident or incidents arise not from the production plant but from the hydrogen piping system during the frequent adjustment or re-connection of the fittings or valves. Moreover, among the three current industrial hydrogen production processes of electrolysis, steam reforming with natural gas or with methanol, the methanol process is the simplest one and requires the lowest theoretical energy in the conversion to hydrogen as mentioned above. 
Currently, over 280 HRS has been built in Japan. Germany, US, Korea and mainland China, most of them rely on the central supply mode by merchant hydrogen; this could be due to the lack of high-efficient and reliable small-scale onsite hydrogen production facility in these countries. The availability of small-scale onsite methanol hydrogen generator in Taiwan has shown its advantages of lower hydrogen cost, compact size and high efficiency with low energy consumption for hydrogen prodduction. The modular supply of methanol hydrogen generator provides a flexibility of expansion in the later time when increased hydrogen filling requires a larger capacity.

One reason the HRS investor prefers haul-in hydrogen with tube trailer may be due to its lower initial investment cost although the hydrogen cost may be twice more expensive. Finally, the drivers of FCEV or FCV today may be motivated stronger by the environmental concern and by the interest in new technology innovation with less concern to the actual cost of driving. In future, however, with more FCV or FCEV into the market, the economical concern and convenient service may become important that the pressure of lowering the cost of hydrogen and greater availability of HRS may become a major concern of the driver to choose one HRS over the other; then the shift to the more abundant smaller onsite production of hydrogen to lower the hydrogen cost and to provide easier access may become the eminent issue.

\section{Conclusion}

The cost of hydrogen, the safety concern and the size of land demand for hydrogen supply in a HRS are influenced by the choice of the hydrogen supply modes. The central supply mode with the high compressed merchant hydrogen hauled-in by the long tube trailer requires higher energy consumption, has more expensive hydrogen cost and the larger land area for the facility than the distributed supply mode if an onsite hydrogen generator from methanol is used.

The storage of large volume of high-pressure hydrogen in a crowded area would be a potential threat to the public safety and may cause public resistant to the installation of HRS. Thus, the absence or reduction of storing high-pressure hydrogen by an onsite production of hydrogen will be a welcome to public concern of safety hazard particularly when public acclaim for better hydrogen safety rises.

The current HRS capacity appears to be over sized as judged from the two reports on the filling percentage of the station capacity; perhaps smaller station with onsite production of hydrogen a modular facility with $200-300 \mathrm{~kg} / \mathrm{D}$ or smaller capacity distributed in community or combined with the existing gas stations may offer safer, more economic and convenient service.

\section{Conflicts of Interest}

The authors declare no conflicts of interest regarding the publication of this paper. 


\section{References}

Amos, W. A. (1998). Cost of Storing and Transporting Hydrogen. NREL/TP-5700-2510. https://doi.org/10.2172/6574

Bossel, U., \& Eliasson, B. (2003). Energy and the Hydrogen Economy. https://afdc.energy.gov/files/pdfs/hyd_economy_bossel_eliasson.pdf

California Air Resource Board (CAR Board) (2019). 2019 Annual Evaluation of Fuel Cell Electric Vehicle Deployment \& Hydrogen Fuel Station Network Development. https://ww2.arb.ca.gov/sites/default/files/2019-07/AB8_report_2019_Final.pdf

Cardella, U., Decker, L., \& Klein, H. (2017). Economically Viable Large-Scale Hydrogen Liquefaction. IOP Conference Series: Materials Science and Engineering, 171, Article ID: 012013. https://doi.org/10.1088/1757-899X/171/1/012013

E4 Tech (2019). The Fuel Cell Industry Review 2019.

Franco, A., \& Casarosa, C. (2014). Thermodynamic and Heat Transfer Analysis of LNG Energy. Journal of Physics: Conference Series, 547, Article ID: 012012. https://doi.org/10.1088/1742-6596/547/1/012012

Fuelcellsworks (2019). Gexcon. KJorbo Hydrogen Station. https://fuelcellsworks.com/news/nel-issues-update-regarding-incident-at-kJorbo/

Heid, B., Linder, M., Orthofer, A., \& Wilthaner, M. (2017). Hydrogen: The Next Wave for Electric Vehicle. New York: McKinsey \& Company.

Herald, The Korea (2019). Hydrogen Tank Explosion Kills 2 in Gangneung. http://www.koreaherald.com./

Hydrogen Tools/Hydrogen Analysis Resource Center (2019). International Hydrogen Fueling Station. https://h2tools.org/hyarc/hydrogen-data/international-hydrogen-fueling-stations

IEA (2019). Hydrogen-Tracking Clean Energy Progress. https:/www.iea.org/tcep/\%20energyintegration/\%20hydrogen

Joseph, E. S., \& Pratt, H. (2017). Comparison of Conventional vs. Modular Hydrogen Refueling Stations and on-Site Production vs. Delivery, Sandia National Laboratories. SAND2017-2832.

https://www.energy.gov/sites/prod/files/2017/03/f34/fcto-h2first-reference-station-pha se2-2017.pdf

Lewis, S. (2013). Maximpact Blog, Japan Builds "Hydrogen Society of the Future". http://maximpactblog.com/japan-builds-hydrogen-society-of-the-future/

Liu, X., Zhang, S., Dong, J., \& Xua, X. (2016). A Short-Term Analysis of Hydrogen Demand and Refueling Station Cost in Shenzhen China. Energy Procedia, 104, 317-322. https://doi.org/10.1016/j.egypro.2016.12.054

Melaina, M., \& Penev, M. (2013). Comparing Hydrogen Station Cost Calculator Results with other Recent Estimates. Technical Report, NREL/TP-5400-56412. https://doi.org/10.2172/1260510

Nagashima, M. (2018). Japan's Hydrogen Strategy and Its Economic and Geopolitical Implications. Études de L'IIfri, Ifri (p-6).

National Research Council and US National Academy of Engineering (2004). Hydrogen Economy. Chapter 3.

Newsom, G. (2019). 2019 Annual Assessment of Time and Cost Needed to Attain 100 Hydrogen Refueling Station in California. CEC-00-2019-039.

Ohi, J. M., \& Nicholas, V. (2016). Hydrogen Fuel Quality Specifications for Polymer Electrolyte Fuel Cells in Road Vehicles. Fuel Cell Technologies Office, US-DOE. 
Pena, L. (2019). Hydrogen Explosion Shakes Santa Clara Neighborhood. ABC7 San Francisco.

Private Communication with Green Hydrotec Inc (2019). http://www.grnhydrotec.com/

Rei, M. H. (2020). The Role of Methanol in the Hydrogen Energy (To Be Published).

Saur, G., Sprik, S., Kurtz, J., Onorato, S., Gilleon, S., \& Winkle, E. (2019). Hydrogen Station Data Collection and Analysis. Project ID: TA014.

https://www.hydrogen.energy.gov/pdfs/review19/ta014_sprik_2019_o.pdf

Tetsufumi, I. (2018). Status of Hydrogen Fueling Stations Technologies in Japan in International Hydrogen Infrastructure Workshop, Boston, MA, Sponsored by US-DOE. https://www.energy.gov/sites/prod/files/2018/10/f56/fcto-infrastructure-workshop-201 8-16-ikeda.pdf

US Department of Energy (1991). Assessment of Costs and Benefits of Flexible and Alternative Fuel Use in the US Transportation Sector. Technical Report No. 7, Environmental, Health, and Safety Concerns.

Wandel, M. (2018). China's Hydrogen Economy. https://www.respectmyplanet.org/publications/\%20fuel-cells/chinas-hydrogen-econom Y

Weinert, J. X., Liu, S., Ogden, J. M., \& Ma, J. (2007). Hydrogen Refueling Station Cost in Shanghai. International Journal of Hydrogen Energy, 32, 4089-4100. https://doi.org/10.1016/j.ijhydene.2007.05.010

Yang, C., \& Ogden, J. (2007). Determining the Lowest-Cost Hydrogen Deliver Mode. https://doi.org/10.1016/j.ijhydene.2006.05.009

Zalosh, R. G., \& Short, T. P. (1978). Compilation and Analysis of Hydrogen Accident Report. Final Technical Report, FMRC J.I. 4A7NO.RG. RC-T-54, for Div. Operational \& Environmental Safety, US DOE, EE-77-C 02-4447. 